\title{
MATURAÇÃO DE SEMENTES DE PIMENTA EM FUNÇÃO DE ÉPOCAS DE COLHEITA DOS FRUTOS
}

\author{
Maturation of pepper seeds as a function of fruit harvest times
}

\begin{abstract}
Josiane Cantuária Figueiredo ${ }^{*}$; Andréia Márcia Santos de Souza David²; Cleisson Dener da Silva ${ }^{3}$; Hugo Tiago
\end{abstract} Ribeiro Amaro²; Dorismar David Alves²

\footnotetext{
${ }^{1}$ Mestranda em produção vegetal; departamento de Ciências Agrárias da Universidade Estadual de Montes Claros, na avenida Reinaldo Viana, 2630 - Bico da Pedra, CEP 39440-000, Janaúba/MG, Brasil. josycantuaria@yahoo.com.br, (autor para correspondência*)

2 Professores; departamento de Ciências Agrárias da Universidade Estadual de Montes Claros, na avenida Reinaldo Viana, 2630 Bico da Pedra, CEP 39440-000, Janaúba/MG, Brasil. andreia.david@unimontes.br, htiagoamaro@yahoo.com.br, dorismar.alves@unimontes.br

${ }^{3}$ Acadêmico do curso de agronomia; departamento de Ciências Agrárias da Universidade Estadual de Montes Claros, na avenida Reinaldo Viana, 2630 - Bico da Pedra, CEP 39440-000, Janaúba/MG, Brasil. denercleisson5@hotmail.com
}

\section{Artigo enviado em 20/03/2017, aceito em 01/08/2017 e publicado em 29/09/2017.}

Resumo: A determinação da maturidade e do momento adequado de colheita são aspectos importantes a serem considerados na produção de sementes de alta qualidade. Objetivo deste trabalho foi estudar o processo de maturação de sementes de pimenta, variedade Dedo-de-moça, com a finalidade de determinar a época de maturidade fisiológica das sementes, bem como a tolerância das mesmas ao retardamento de colheita. A partir de $50 \%$ dos botões florais em antese, as flores foram etiquetadas e os frutos foram colhidos aos 30, 45, 60, 75, e 90 dias após a antese (DAA), sendo avaliados quanto à coloração. A qualidade fisiológica das sementes foram avaliadas quanto ao teor de água, massa de matéria seca, germinação, primeira contagem de germinação, índice de velocidade de emergência e envelhecimento acelerado. As sementes atingem o máximo acúmulo de matéria seca (maturidade de massa) aos 74 dias após antese, sendo que a maturidade fisiológica das sementes (máximo de germinação e vigor) ocorre no período de 71 a 81 dias após a antese, que representa uma soma térmica de 1064,28 a 1128,53 graus dias.

Palavras-chave - antese, Capsicum baccatum var. pendulum, época de colheita.

\begin{abstract}
The determination of physiological maturity and the appropriate harvest time are important aspects to be considered in the production of high quality seeds. The objective of this research was to study the process of maturation of pepper seeds, young finger variety, in order to determine the physiological maturity time of the seeds, as well as the tolerance of the seeds to the harvest delay. From $50 \%$ of the floral buds in anthesis, flowers were labeled daily and fruits were harvested at 30, 45, 60, 75, and 90 days post anthesis (DAA). At each harvest season, fruits were evaluated for weight and diameter. To determine the physiological quality, seeds were evaluated for water content, dry matter mass, germination, first germination count, rate of emergence and accelerated aging. The seeds reached the maximum accumulation of dry matter (mass maturity) at 74 days after anthesis, and the physiological maturity of the seeds (maximum germination and vigor) occurs in the period from 71 to 81 days after anthesis, which represents a sum Temperatures from 1064.28 to 1128.53 degrees days.
\end{abstract}

Keywords - before and, Capsicum baccatum var. pendulum; harvest season

\section{INTRODUÇÃO}

A pimenta Dedo-de-moça (Capsicum baccatum var. pendulum) pertence à família Solanaceae e ao gênero botânico Capsicum, que envolve as pimentas, pimentões, berinjelas e tomates. É conhecida popularmente como pimenta calabresa sendo bastante consumida no Brasil, dominando assim o comércio das especiarias picantes sendo considerado símbolo da culinária mundial. (CONFORTI et al., 
2007). O Seu cultivo ocorre preferencialmente nas regiões sudeste, centro-oeste e nordeste, sendo que os principais estados produtores são Minas Gerais, São Paulo, Rio de Janeiro, Ceará e Bahia (REBOUÇAS et al., 2013).

Nos últimos anos, a importância pela cultura vem se destacando junto às indústrias farmacêuticas, alimentícias e de cosméticos, sendo utilizadas nos mais diversos fins, para o consumo in natura, na fabricação de geleias, molhos, conservas e remédios. Devido à crescente demanda por esses produtos, o interesse pela cultura da pimenta, principalmente pela variedade Dedo-de-moça, vem aumentando grandemente entre as empresas e produtores (RIBEIRO et al., 2008).

O cultivo de qualquer espécie de planta propagada sexualmente, incluindo as pimentas, deve começar com a utilização de sementes de qualidade, no entanto, uma das principais limitações encontradas para o seu cultivo é a baixa oferta de sementes de qualidade, visto que o processo de maturação dessa espécie é desuniforme, devido à mesma apresentar hábito de crescimento indeterminado, com florescimento e frutificação ocorrendo de forma contínua (ABUD et al. 2013; VIDIGAL et al., 2009).

Assim, as pimentas apresentam na época da colheita, frutos e sementes em diversos estádios de desenvolvimento e graus de maturação fisiológica, o que dificulta a determinação da época de maturidade fisiológica das sementes e, consequentemente, o momento ideal de colheita, para a obtenção de sementes com alta qualidade fisiológica (CARVALHO; NAKAGAWA, 2012; VIDIGAL et al., 2009).

Diante deste contexto, objetivou-se com este trabalho estudar o processo de maturação de sementes de pimenta, variedade Dedo-de-moça, com a finalidade de determinar a época de maturidade de massa e da maturidade fisiológica das sementes, bem como a tolerância das mesmas ao retardamento de colheita.

\section{MATERIAL E MÉTODOS}

O campo de produção de sementes foi instalado na Área Experimental do Departamento de Ciências Agrárias (DCA) da Universidade Estadual de Montes Claros (Unimontes) em Janaúba-MG (1547'50"S, 4318’31'O, altitude de $516 \mathrm{~m}$ ) no período de setembro de 2015 a fevereiro de 2016. As análises laboratoriais foram realizadas no Laboratório de Análise de Sementes da Unimontes, Janaúba, MG.
Foram utilizadas sementes de pimenta da variedade Dedo-de-moça.

O clima da região segundo classificação de Koppen, é do tipo "AW" (tropical com inverno seco), com temperatura e precipitação média anual de $25{ }^{\circ} \mathrm{C}$ e $900 \mathrm{~mm}$ respectivamente, e umidade média relativa do ar de $65 \%$.

O delineamento experimental empregado foi o inteiramente casualizado (DIC), com cinco épocas de colheita dos frutos, que consistiram nos tratamentos, com cinco repetições por tratamento.

Para a produção de mudas, que ocorreu em casa de vegetação climatizada, as sementes foram semeadas em bandejas de poliestireno expandido (isopor) com 128 células, contendo substrato comercial Bioplant ${ }^{\mathbb{R}}$. Aos quarenta e cinco dias após a semeadura, quando as plântulas apresentavam de quatro a seis folhas definitivas, realizou-se o transplantio das mudas.

No campo, o preparo do solo consistiu de aberturas de covas com auxílio de enxada e as plantas foram dispostas em uma área de $72 \mathrm{~m}^{2}$ (9 $\mathrm{m}$ x $8 \mathrm{~m}$ ) com espaçamento de $1,0 \times 1,0 \mathrm{~m}$ entre plantas. A adubação foi baseada nas características químicas do solo na camada de 0 a $20 \mathrm{~cm}$ de profundidade e de acordo as recomendações para a cultura da pimenta, que constou da aplicação de $500 \mathrm{~kg} \mathrm{ha}^{-1}$ de $\mathrm{P}_{2} \mathrm{O}_{5}, 60$ $\mathrm{kg} \mathrm{ha}^{-1}$ de $\mathrm{K}_{2} \mathrm{O}$ e $67 \mathrm{~kg} \mathrm{ha}^{-1}$ de $\mathrm{N}$, aplicadas na cova por ocasião do transplantio das mudas, e seis adubações de cobertura com $39 \mathrm{~kg} \mathrm{ha}^{-1}$ de $\mathrm{K}_{2} \mathrm{O}$ e 43 $\mathrm{kg} \mathrm{ha}^{-1}$ de $\mathrm{N}$, aplicadas no intervalo de 15 dias entre cada adubação (ALVARES et al., 1999).

Durante a fase de florescimento, as flores foram etiquetadas diariamente de forma que a quantidade de sementes atendesse à demanda das análises realizadas posteriormente. A colheita dos frutos foi realizada manualmente aos 30, 45, 60, 75 e 90 dias após a antese (DAA). Após a colheita, os frutos de pimenta foram transportados ao laboratório de sementes e tiveram os seus aspectos visuais registrados através de fotografias.

Em seguida os frutos foram cortados com auxílio de um estilete e tiveram suas sementes extraídas manualmente, lavadas em água corrente e colocadas para secar em condições ambientais por 48 horas.

O teor de água das sementes foi determinado conforme metodologia prescrita nas Regras para Análise de Sementes - RAS (Brasil, 2009), utilizando o método da estufa, a $105 \pm 3^{\circ} \mathrm{C}$, durante 24 horas, com cinco repetições de cinquenta sementes por tratamento, sendo os resultados expressos em porcentagem (\%). Simultaneamente, foi determinado 
o peso da matéria seca das sementes, sendo os resultados expressos em \%.

Para o teste de germinação, as sementes foram semeadas sobre duas folhas de papel germitest, umedecidas com água destilada em volume equivalente a 2,5 vezes o seu peso seco e dispostas em caixas plásticas tipo gerbox. Após esse procedimento, as caixas contendo as sementes foram mantidas em germinador digital previamente regulado à temperatura de $30^{\circ} \mathrm{C}$ e luz constante. As avaliações foram feitas no sétimo (primeira contagem da germinação) e décimo quarto dia após a semeadura, e os resultados expressos em percentagem de plântulas normais, de acordo com os critérios estabelecidos pelas RAS (BRASIL, 2009).

Para o teste de envelhecimento acelerado, utilizou-se uma camada única de 300 sementes, distribuídas uniformemente sobre uma tela acoplada às caixas de plástico tipo gerbox, contendo, no fundo, $40 \mathrm{~mL}$ de água destilada. As caixas contendo as sementes foram tampadas e mantidas em câmara BOD, a $42{ }^{\circ} \mathrm{C}$ por $96 \mathrm{~h}$ (BHERING et al., 2006). Decorrido este período, cinco repetições de 50 sementes foram submetidas ao teste de germinação, conforme metodologia descrita anteriormente. Os resultados foram expressos em porcentagem de plântulas normais obtidas aos sete dias após a semeadura.

Os dados foram testados quanto à normalidade e homogeneidade de variância. Em seguida foram submetidos à análise de variância e regressão em nível de 5\% pelo teste " $F$ ". As estimativas dos parâmetros da regressão foram avaliadas pelo teste " $t$ " em nível de $5 \%$ de significância.

\section{RESULTADOS E DISCUSSÃO}

A coloração dos frutos variou de acordo com as épocas de colheitas (Figura 1). Aos 30 DAA os frutos apresentavam-se completamente verdes. Com a degradação da clorofila, pigmento responsável pela coloração verde dos frutos e hortaliças, e pelo acúmulo de outros pigmentos como carotenoides e antocianinas (Taiz; Zeige, 2009) ocorreu alteração no exocarpo dos frutos para a coloração verde com manchas alaranjadas quando os mesmos foram colhidos aos 45 DAA. Aos 60 DAA houve completa mudança de coloração dos frutos, apresentando-se o exocarpo vermelho alaranjado. Já aos 75 DAA os frutos apresentavam a coloração predominantemente vermelha, sendo esta bastante intensificada aos 90
DAA. Verifica-se ainda que aos 90 DAA é possível visualizar uma alteração na turgescência dos frutos, possivelmente devido ao retardamento da colheita dos mesmos.

De modo geral, a coloração do exocarpo dos frutos de pimenta é uma característica que ajuda detectar a época em que as sementes atingiram maturidade fisiológica, podendo ou não coincidir com o máximo de germinação e vigor (VINDIGAL et al., 2011).
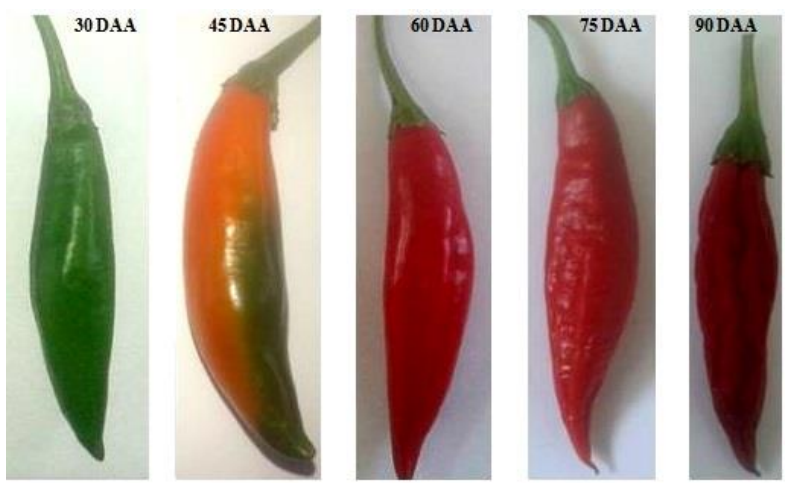

Figura 1: Aspecto visual dos frutos de pimenta, variedade Dedo-de-moça, colhidos aos 30; 45; 60; 75 e 90 DAA.

A matéria seca das sementes, que, aos 45 dias após a antese era de $3,17 \mathrm{mg} / \mathrm{semente}$, aumentou acentuadamente até atingir o máximo conteúdo de matéria seca de $4,20 \mathrm{mg} /$ semente aos $74 \mathrm{DAA}$, que correspondeu a 1064,28 graus-dia definindo este ponto como de maturidade de massa (Figura 2), conforme proposto por ELLIS; PIETA FILHO (1992). Nesta fase de desenvolvimento das sementes os frutos apresentaram coloração vermelha (Figura 2).

A partir dos 77 DAA houve uma pequena redução na matéria seca das sementes, atingindo 3,82 $\mathrm{mg} / \mathrm{semente}$ aos 90 dias após a antese (Figura 2). Possivelmente, esta redução está associada às perdas pela respiração das sementes em função das condições climáticas observadas durante a condução do experimento (DAVID et al., 2003).

Após as sementes atingirem o máximo acúmulo de matéria seca, estas não mais recebem fotoassimilados e tornam-se independentes da plantamãe. A partir deste ponto quando o conteúdo de água ainda é muito elevado, entre $30-40 \%$, como é o caso das sementes de pimenta, o metabolismo permanece ativo e pode desencadear na semente o processo de deterioração (CARVALHO; NAKAGAWA, 2012). 
Assim, o atraso na colheita pode levar a queda do seu potencial fisiológico.

As modificações no teor de água das sementes (Figura 2) ocorreram de maneira inversa ao acúmulo de matéria seca. Inicialmente, aos $30 \mathrm{DAA}$ quando as sementes encontravam-se imaturas o teor de água era de $63 \%$, caindo acentuadamente, até atingir $21 \%$ aos 90 DAA (última colheita).

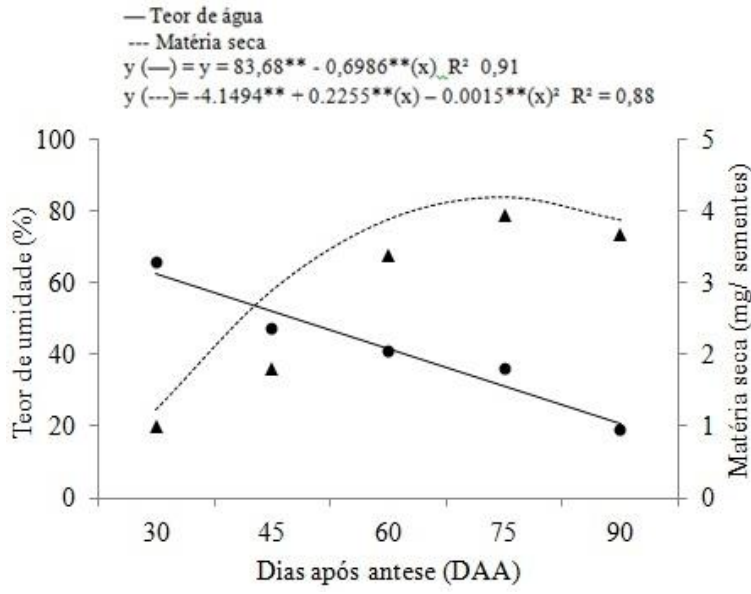

Figura 2: Teor de água e acúmulo de matéria seca de sementes de pimenta, variedade Dedo-de-moça, em função dos dias após a antese (épocas de colheita).

O alto teor de água nessa fase de maturação é necessário tanto para a translocação de metabólicos da planta para as sementes, quanto para expansão celular (Bewley et al., 2013), além de ser importante devido à necessidade das sementes sintetizar e metabolizar materiais de reserva que ocorrem em meio aquoso (Marrocos et al., 2011), tais reservas como as proteínas, amidos e lipídeos (CARVALHO; NAKAGAWA, 2012).

Aos 74 DAA, período em que ocorreu o máximo acúmulo de matéria seca nas sementes (maturidade de massa), as mesmas se encontravam com o teor de água de 35\%. Segundo Carvalho e Nakagawa (2012) o processo de desidratação em sementes de frutos carnosos, como é o caso do fruto da pimenta é lento, e ao atingir maturidade fisiológica as sementes ortodoxas se encontram com teor de água dentro da faixa de 30 a $50 \%$. Neste caso, as sementes não sofrem grandes oscilações no seu teor de água e nem passam pela fase rápida desidratação, em função da umidade relativa no interior do fruto (DEMIR et al., 2002).
Resultados próximos aos observados no presente trabalho foram obtidos por Abud et al. (2013), os quais verificaram que aos 70 DAA o teor de água das sementes de pimenta malagueta e biquinho foi de aproximadamente 39 e 36\%, respectivamente. Já Queiroz et al. (2011) observaram que sementes de pimenta habanero apresentam teor de água de 56\% aos 67 DAA. Entretanto, deve-se ressaltar que os resultados deste trabalho em associação com os de Abud et al. (2013), Vidigal et al. (2011) e Queiroz et al. (2011) corroboram os trabalhos de Daynard (1972) e Hunter et al. (1991), os quais argumentaram que embora seja amplamente utilizado, o teor de água das sementes não é um bom indicador de maturidade fisiológica por sofrer influências ambientais e genéticas.

A porcentagem de geminação das sementes extraídas de frutos verdes (30 DAA) foi praticamente nula (3\%) (Figura 3). Nesta fase de desenvolvimento nem todas as sementes encontram-se com embrião totalmente formado, possuindo assim imaturidade para germinar. Adiciona-se a isso também a possibilidade de ocorrência de dormência das sementes nesse estádio inicial, o que afeta diretamente seu real potencial de germinação (JUSTINO et al., 2015). Além disso, nesta época de colheita as sementes apresentavam elevado teor de água (63\%), e que segundo Abud et al. (2013) as sementes estariam acumulando reservas necessárias para o processo germinativo

A partir dos 30 DAA foram verificados acréscimos na porcentagem de germinação das sementes até aproximadamente 71 DAA, que correspondeu a 1064,28 graus-dia período em que ocorreu a máxima germinação $(86 \%)$, antes das sementes atingiram a maturidade fisiológica com base no máximo acúmulo de matéria seca (Figura 3), que ocorreu aos 74 dias após a antese. Os resultados do presente trabalho estão de acordo com os encontrados por Abud et al. (2013); Oliveira et al. (2014); e David et al. (2003) que observaram máxima germinação antes do ponto de maturidade de massa, com base no acúmulo de matéria seca das sementes.

Vale ressaltar que a máxima germinação ocorrida aos 70 dias após a antese coincidiu com o elevado valor no teor de água de $35 \%$. Nesse sentido, Abud et al. (2013) relatam que mesmo ainda apresentando alto teor de água, as sementes já adquirem elevado potencial germinativo devido principalmente ao acúmulo de reservas que ocorrem em meio aquoso. 
A porcentagem de germinação na época em que as sementes atingiram a maturidade fisiológica com base no máximo acúmulo de matéria seca foi de 85\% (74 DAA), reduzindo para 73\% aos 90 dias após a antese. Esses resultados demonstram um decréscimo de aproximadamente 14,11\% na germinação dos 74 até aos 90 DAA. Ressalta-se que embora tenha ocorrido redução na germinação das sementes, as mesmas se encontram dentro do percentual mínimo recomendado para a comercialização de sementes básicas, que é de $70 \%$ (BRASIL, 2012).

Observando-se os resultados de vigor, avaliado pelo teste de primeira contagem, verifica-se máxima germinação na primeira contagem aproximadamente aos 79 DAA com valores de $76 \%$ (Figura 3).

A partir do ponto máximo ocorreu decréscimo até aos 90 DAA, em que foram observados valores de germinação de $69 \%$. Possivelmente esta redução é devido à deterioração das sementes no campo em decorrência do retardamento da colheita. Os resultados mostraram que a queda no vigor pelo teste de primeira contagem foi mais acentuada do que a germinação, à medida que se retardava a colheita.
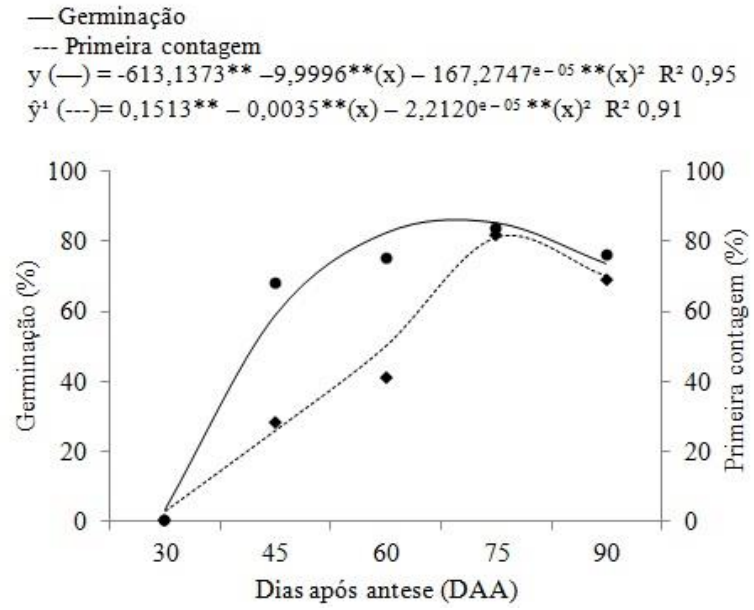

Figura 3. Germinação e primeira contagem da germinação de sementes de pimenta, variedade Dedode-moça, em função dos dias após a antese (épocas de colheita).

Verifica-se, a que aos 30 DAA a porcentagem de germinação após o envelhecimento acelerado foi de $8 \%$, atingindo o máximo de germinação aproximadamente aos 81 DAA (95\%) (Figura 4). A partir do ponto máximo, o vigor das sementes decresceu, provavelmente devido à deterioração no campo, em consequência do atraso na colheita. Esta queda do vigor com base nos valores do teste de envelhecimento acelerado, no período compreendido entre o ponto máximo até a última colheita, foi de $26,27 \%$.

Vidigal et al. (2006), avaliando a qualidade fisiológica de sementes de tomate em função da idade e do armazenamento pós colheita dos frutos, concluíram que, baseado nos resultados de vigor, com o uso do teste de envelhecimento acelerado, as sementes deveriam ser colhidas aos 50 e 60 DAA, para que não ocorresse perda na qualidade fisiológica.

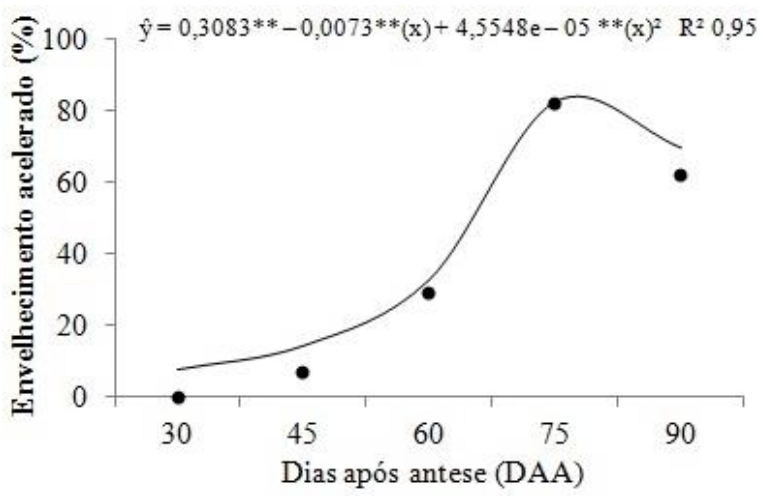

Figura 4: Envelhecimento acelerado de sementes de pimenta, variedade Dedo-de-moça, em função dos dias após a antese (épocas de colheita).

\section{CONCLUSÃO}

As sementes atingem o máximo de matéria seca (maturidade de massa) aos 74 dias após antese, sendo que a maturidade fisiológica das sementes (máximo de germinação e vigor) ocorre entre 70 a 81 dias após a antese, que representa uma soma térmica de 1064,28 a 1128,53 graus dias.

\section{REFERÊNCIAS}

ABUD, H. F.; ARAUjO, E. F.; ARAUJO, R. F.; ARAUJO, A. V.; PINTO, C. M. F. Qualidade fisiológica de sementes das pimentas malagueta e biquinho durante a ontogênese. Pesquisa agropecuária brasileira, v. 48, n.12, p. 1546-1553, dez. 2013. 
ALVARES V. V.H.; NOVAES, R. F.; BARROS, N. F.; CANTARUTTI, R. B.; LOPES, A.S. Interpretação dos resultados das análises de solos. In: RIBEIRO, A.C.; GUIMARAES, P.T.G.; ALVAREZ V., V.H. (Ed.). Recomendação para o uso de corretivos e fertilizantes em Minas Gerais: 5. Aproximação. Viçosa: Comissão de Fertilidade do Solo do Estado de Minas Gerais, 1999. p. 25-32

BEWLEY, J. D.; BRADFORD, K. J.; HILHORST, H. W. M.; NONOGAKI, H. Seeds: physiology of development, germination and dormancy. 3. ed. New York: Springer, 2013. 392 p.

BHERING, M.C.; DIAS, D.F.C.; VIDIGAL, D.S.; NAVEIRA, D.S.P. Teste de envelhecimento acelerado em sementes de pimenta. Revista Brasileira de Sementes, v.28, n. 3, p. 64-71, dez. 2006. Disponível em http://www.scielo.br/pdf/rbs/v28n3/10.pdf

BRASIL. Ministério da Agricultura, Pecuária e Abastecimento. Regras para análise de sementes: Secretaria de Defesa Agropecuária. Brasília: Mapa/Acessoria de comunicação social, 2009. 399 p. BRASIL. Ministério da Agricultura, Pecuária e Abastecimento. Portaria n ${ }^{\circ} 111$, de 4 de setembro de 2012. Estabelece os padrões de identidade e qualidade para a produção e a comercialização de sementes de espécies olerícolas, condimentares, medicinais e aromáticas, disposto em anexo. Diário Oficial [da] República Federativa do Brasil, 5 set. 2012. Seção 1, p.3-4.

CARVALHO, N. M.; NAKAGAWA, J. Sementes: ciência, tecnologia e produção. 5 ed. Jaboticabal: FUNEP, 2012. 590 p.

CONFORTI, F.; STATTI, G.A.; MENICHINI, F. Chemical and biological variability of peper fruits (Capsicum annumvar. Acuminatum L.) in relation to maturity stage. Food Chemistry, v.102, p.1096-1104, 2007.

DAYNARD, T.B. Relationships among black layer formation, grain moisture percentage, and heat unit accumulation in corn. Agronomy Journal, v.64, n. 6, p.716-719, 1972.

DAVID, A. M. S. S.; ARAÚJO, E. F.; MIRANDA, G. V.; DIAS, D. C. F. S.; GALVÃO, J. C. C.; CARNEIRO, V. Maturação de sementes de milhopipoca. Revista Brasileira de Milho e Sorgo, v. 2, n. 3, p. 121-131, 2003.
DEMIR, I.; MAVI, K.; SERMENLI; T.; OZCOBAN, M. Seed development and maturation in Aubergine (Solanum melongena L.). Gartenbaunissenschaft, v.67, n.4, p. 148-154, 2002.

ELLIS, R. H.; PIETA FILHO, C. Seed development and cereal seed longevity. Seed Science Research, v. 2, p. $9-15,1992$.

JUSTINO, E. V.; BOITEUX, L. S.; FONSECA, M. E.; SILVA FILHO, J. G.; NASCIMENTO, W. M. Determinação da maturidade fisiológica de sementes de pimenta dedo de moça Capsicum baccatum var. pendulum. Horticultura Brasileira, v. 33, n. 3, p. 324-331, 2015.

HUNTER, J.L.; TEKRONY, D.M.; MILES, D.F.; EGLI, D.B. Corn seed maturity indicators and their relationship to uptake of Carbon- 14 assimilate. Crop Science, v.31, n. 5, p.1309-1313, 1991.

MARrocos, S. D. T. P.; MEDEIROS, M. A. D.; GRANGEIRO, L. C.; TORRES, S. B.; LUCENA, R. R. M. D. Maturação de sementes de abobrinha menina brasileira. Revista Brasileira de Sementes, v. 33, n. 2, p. 272-278, 2011.

OLIVEIRA, M. B.; DAVID, A. M. S. S.; AMARO, H. T. R.; ASSIS, M. O.; RODRIGUES, B. R. A.; ASPIAZÚ, I.; CARVALHO, A. J. Épocas de colheita e qualidade fisiológica de sementes de crambe. Semina: Ciências Agrárias, v.35, n. 4, p.1785-1792, 2014.

RIBEIRO CSC; HENZ GP. 2008. Processamento. In: RIBEIRO CSC; LOPES CA; CARVALHO SIC; HENZ GP; REIFSCHNEIDER FJB (Org.). Pimentas Capsicum. Brasilia: Embrapa Hortaliças, 2008, v.1, p. 157-171.

TAIZ, L. ZEIGER, E. Fisiologia vegetal. 4. ed. Porto Alegre: Artmed, 2009, 719 p.

QUEIROZ, L.A.F.; VON PINHO, E.V. DE R.; OLIVEIRA, J.A.; FERREIRA, V. DE F.; CARVALHO, B.O.; BUENO, A.C.R. Época de colheita e secagem na qualidade de sementes de pimenta habanero yellow. Revista Brasileira de Sementes, v.33, n.3, p.472-481, 2011. 
REBOUÇAS, T.N.H.; VALVERDE， R.M.V.; TEXEIRA, H.L. Bromatologia da pimenta malagueta in natura e processada em conserva. Horticultura Brasileira, v.31, n.1, p. 163-165,2013.

VIDIGAL, D. DE S.; DIAS, D.C.F. DOS S.; DIAS, L.A. DOS S.; FINGER, F.L. Changes in seed quality during fruit maturation of sweet pepper. Scientia Agricola, v.68, n.5, p.535-539, 2011.
VIDIGAL, D. DE S.; DIAS, D.C.F. DOS S.; NAVEIRA, D. DOS S.P.C.; ROCHA, F.B.; BHERING, M.C. Qualidade fisiológica de sementes de tomate em função da idade e do armazenamento pós-colheita dos frutos. Revista Brasileira de Sementes, v.28, n.3, p.87-93, 2006.

VIDIGAL, D. S.; DIAS, D. C. F. S.; PINHO, E. V. R. V.; DIAS, L. A. S. Alterações fisiológicas e enzimáticas durante a maturação de sementes de pimenta (Capsicum annuum L.). Revista Brasileira de Sementes, v. 31, n. 2, p. 129-136, 2009. 